\title{
FERRAMENTA DE PADRONIZAÇÃO PARA AVALIAÇÃO DE TRABALHOS DE DESIGN EM
}

3D

Raphael Argento de Souza

Escola Superior de Desenho Industrial - UERJ

raphaelargento@gmail.com

Andre Soares Monat

Escola Superior de Industrial - UERJ

andresmonat@yahoo.com.br

Washington Dias Lessa

Escola Superior de Desenho Industrial - UERJ

washington.lessa@gmail.com

Resumo: Uma das maneiras mais frequentes de se avaliar um estudante de Design é através da realização de trabalhos práticos. No mercado atual não existem ferramentas criadas para auxiliar o docente na atividade de avaliação quando relacionados à disciplinas que envolvem softwares 3D. A proposta deste trabalho é apresentar uma ferramenta, criada através da linguagem de programação MaxScript, para auxiliar a avaliação e padronização de feedback de trabalhos acadêmicos, realizados no campo da representação visual através de softwares de modelagem e animação 3D. Os aspectos quantitativos e qualitativos são, assim, ressaltados como pontos-chave desta proposta.

Palavras-chave: Design, Educação, Avaliação, Ferramentas 3D.

Abstract: This paper proposes the use of a digital tool inside 3ds Max in order to standardize the feedback provided by teachers to Design Students. It's aim is to improve the feedback's quality and allow students to improve their abilities through it.

Keywords: Design, Education, Evaluation, 3D tools. 


\section{INTRODUÇÃO}

A atuação do Designer na área acadêmica não é algo recente, mas gradualmente está sendo ampliada através da expansão das universidades e da inserção deste profissional em cursos de graduação tradicional e tecnólogos em nosso país.

Considerando que a área do Design pode se desenvolver através do conceito de "Reflexão-na-ação" (SCHÖN, 1981), o Designer possui um meio bastante particular de refletir sobre o seu trabalho enquanto o pratica. Na área acadêmica, uma das maneiras frequentes de se ensinar a prática do Design é através da apresentação de técnicas e da própria ação projetual - cujas etapas são apresentadas, discutidas, revistas e aprimoradas em sala de aula. Assim, é natural que durante o percurso de uma graduação em Design uma das formas de avaliação do desenvolvimento dos estudantes sejam os trabalhos práticos, concernentes às disciplinas oferecidas durante o curso.

O professor torna-se dessa forma o mediador desta abordagem entre teoria e projeto. Entretanto, ao propor projetos ou trabalhos práticos para uma turma numerosa, precisa avaliar os mesmos, ofertando ao discente um feedback que contemple os aspectos abordados na disciplina para que este possa perceber onde encontram-se os problemas de seu projeto. Desta forma ele pode se desenvolver para aprimorar sua reflexão e suas habilidades.

No campo do Design nem sempre estes feedbacks são ofertados através de critérios completamente objetivos, dado que a natureza dos trabalhos desenvolvidos por alunos de Design é, em geral, também diversa, exigindo assim considerações diferentes para cada trabalho.

Poucas são as ferramentas que facilitam a padronização do feedback por parte do professor para estudantes de cursos de graduação presencial. E menos ainda são os cursos que utilizam ferramentas de modelagem tridimensional como parte de seu conteúdo programático, área que vem crescendo nos últimos anos devido ao avanço do setor audiovisual brasileiro. Isto torna-se relevante quando observado o crescimento da participação deste setor na economia (FIRJAN, 2014).

Pesquisas recentes focam em melhorias na avaliação em si (MARINHO, 2010), ou na avaliação da relação entre o Projeto Político Pedagógico e os docentes (BROOKE, 2009), abordando decerto processos de avaliação, mas não uma solução que foque na prática de feedback docente. Algumas englobam ambientes de ensino-aprendizado online (ROMANOWSKI, 2008) ou presencial, entretanto, percebe-se uma carência de ferramentas que podem ser desenvolvidas para o auxílio ao docente no processo de feedback.

Considerando esta questão, este trabalho apresenta uma proposta de ferramenta de auxílio à avaliação que procura solucionar uma lacuna nesta área, mostrando o importante papel da utilização de soluções tecnológicas para melhorar a relação do docente com o corpo discente através da padronização do feedback. Além disso, incentiva a pesquisa na área de interfaces para softwares 3D.

A análise da construção desta ferramenta, suas funcionalidades e sua utilização serão apresentados a seguir. 


\section{METODOLOGIA}

No ensino superior tecnológico, onde a preparação para o mercado é o objetivo principal da formação do aluno, o feedback é um fator diferencial no desenvolvimento do senso crítico dos alunos. Assim como em outras áreas do conhecimento, no campo do Design o feedback como aprendizado no desenvolvimento discente. Especificamente nas graduações em Design uma parcela significativa das avaliações é realizada através de trabalhos práticos.

Ao contrário de uma avaliação escrita, onde o discente tem acesso a um gabarito e após a correção do professor possui a indicação exata de onde seus erros foram cometidos, no Design, a maneira encontrada para apresentar ao aluno onde este precisa se aprimorar é através do feedback aos trabalhos apresentados, muitas vezes realizado de maneira oral.

Atualmente, nem sempre estes feedbacks são realizados de maneira objetiva, de acordo com os planos de ensino elaborados por professores e com as propostas das ementas das disciplinas dos cursos, gerando desconforto para o discente e a sensação de que a avaliação parte de critérios subjetivos, quando deveriam ser objetivos, permitindo o desenvolvimento eficiente do aluno para que o mesmo possa atuar com eficiência nos projetos que desenvolverá em sua carreira.

Ao mesmo tempo, no Ensino Superior, grande parte das atividades docentes são a elaboração de conteúdos para as disciplinas, a avaliação das atividades propostas aos estudantes, e as atividades de pesquisa e extensão. Essas atividades seriam mais bem elaboradas se o docente pudesse avaliar as atividades realizadas por seus alunos de maneira mais eficiente.

Se considerarmos a crítica que DEMO (2012) faz ao instrucionismo, ou seja a atuação de professores em sala de aula, que mais se destinam a ensinar habilidades do que desenvolver o pensamento crítico de seus alunos, pode-se entender que mecanismos que permitem ao docente o melhor aproveitamento do seu tempo para pesquisa e fornecem ao seu estudante os meios através dos quais ele desenvolverá e aprimorará suas habilidades técnicas e cognitivas, são uma vantagem estratégica dentro de cursos de nível superior.

Sendo estes os critérios iniciais, este trabalho foca na atuação do docente que leciona em cursos superiores de Design Gráfico, especificamente em disciplinas relacionadas à softwares de $3 d$, que são na maior parte das vezes relacionadas à execução de técnicas. Acreditamos que o desempenho acadêmico poderia ser mais eficiente se o discente tivesse acesso a um feedback padronizado e o tempo do docente fosse mais efetivo.

Foram levantadas então duas questões. A primeira é a de que a utilização de ferramentas de auxílio às avaliações pode proporcionar agilidade ao docente neste processo e a segunda é a de que este auxílio pode aprimorar a qualidade na elaboração dos feedbacks apresentados aos alunos, mostrando coerência no discurso docente.

A segunda questão é a de que os sistemas de avaliação presentes nas ferramentas de aprendizagem online hoje mais apropriadas às disciplinas que se valem de resultados textuais diretos que aquelas que se baseiam em avaliação de imagens e projetos para receber seus resultados. 
Neste sentido, acredita-se que uma ferramenta que considere critérios quantitativos e possibilite a intervenção qualitativa do professor da área de Criação/Design está entre uma solução que atende os critérios das ferramentas atuais, e permite a avaliação de disciplinas que utilizam a Representação Gráfica em 3D como ferramental para apresentação de projetos em Design Gráfico, padronizando-as.

\section{CONSTRUÇÃO DA FERRAMENTA}

Grande parte das ferramentas educacionais construídas para solucionar as relações de ensino-aprendizagem são destinadas ao desenvolvimento do discente. Entretanto, poucas são direcionadas à melhoria das condições de trabalho e à atuação docente, principalmente na questão relativa ao ensino no setor audiovisual brasileiro.

As ferramentas disponíveis atualmente, visam prioritariamente o ambiente online focando em três objetos: no sistema de apresentação da informação e das propostas de ensino, no ambiente colaborativo, e nos métodos de avaliação.

Os dois primeiros aspectos já foram bastante explorados em ferramentas como o moodle, como estudado por Oliveira e Nardin (2012), enquanto o terceiro aspecto foca no sistema automático de avaliação através de duas vertentes.

Uma delas é a intervenção automática do sistema através de perguntas e respostas de múltipla escolha que, através da resposta do aluno, pode trazer um feedback automático elaborado pelo docente. A outra vertente foca no trabalho exclusivo de avaliação por parte do professor, onde o mesmo precisa verificar cada resposta recebida pelo sistema e avaliá-la segundo critérios pré-estabelecidos, como em questões dissertativas.

Nos cursos de Design Gráfico, grande parte das avaliações são realizadas através de trabalhos práticos. Assim, esses sistemas mostram-se insuficientes para atender as necessidades dos docentes responsáveis pela avaliação do desenvolvimento de seus alunos.

Acrescenta-se a isto o fato de que nas disciplinas onde ferramentas (softwares) específicas são exigidas para a execução de trabalhos práticos, a questão da avaliação via sistemas como o moodle (por exemplo), acabam por não oferecer a possibilidade de avaliação dos arquivos enviados.

Isto reflete negativamente na atividade do docente de ensino em nível superior, que precisa atender às atividades de avaliação, em cursos de Design, através de dois aspectos que se desenvolvem com o desmembrar dos projetos propostos como avaliações para seus alunos:

1 - As atividades elaboradas para se obter respostas repetitivas, que são em primeira instância direcionadas às técnicas utilizadas para elaboração de trabalhos no campo do Design e;

2 - As atividades criativas, que seriam aquelas relativas ao desenvolvimento de soluções projetuais para os problemas propostos nas disciplinas.

Percebe-se que estas duas modalidades se complementam na elaboração dos projetos e podem ser avaliadas separadamente, se necessário, abordando aspectos técnicos por um lado ou aspectos criativos por outro.

Desta forma, apresenta-se aqui, para cursos que abrigam em suas grades curriculares disciplinas de 3D a criação da ferramenta "Corretor de Trabalhos V02", 
que procura atender às demandas de avaliação de trabalhos de Design realizados através de softwares 3D.

No mercado de trabalho o profissional que trabalha com programação para softwares de computação gráfica é chamado de TD (Technical Director), e sua principal responsabilidade é criar ferramentas para auxiliar animadores e modeladores em suas funções. Estas ferramentas realizam tarefas repetitivas ou complexas que demandariam um tempo excessivo de execução por parte dos profissionais de estúdio.

A proposta foi desenvolvida no software 3DS Max, utilizado em diversas faculdades e universidades do Estado do Rio de Janeiro como apoio ao ensino de design para a área do audiovisual, como animação, motion graphics e infografia.

A linguagem utilizada foi o MaxScript, nativa no software 3DS Max, que permite a aquisição de dados externos pelo software e a sua manipulação dentro do ambiente 3D.

A ferramenta foi construída segundo as principais necessidades levantadas:

1. A identificação dos discentes;

2. A identificação da Disciplina avaliada;

3. O carregamento de informações relativas ao feedback a ser devolvido ao aluno;

4. O cálculo da nota a partir das penalidades definidas pelo docente;

5. A gravação dos dados de cada discente;

6. A gravação dos dados de feedback relativos a cada discente em um arquivo externo;

A segunda etapa na criação deste sistema consistiu na elaboração de uma interface que visualmente representasse as funções necessárias à uma correção de trabalhos com feedback, conforme a figura 1. Como o objetivo deste trabalho era criar um protótipo, não foram observadas questões relacionadas à interação humanocomputador e à usabilidade para a criação da mesma.

Os itens de 1 a 4 são os módulos que identificam o discente através de suas ou nome e sua turma, através da localização e do horário.

O item 5 abre uma janela que carrega os critérios pré-definidos pelo professor, através de um arquivo .txt. Neste arquivo .txt a cada quebra de linha o script reconhece a frase digitada como um critério. Foram definidos o número máximo de 8 critérios, carregados no item 6, que é responsável pelas penalidades e pela identificação de onde está o erro encontrado. 


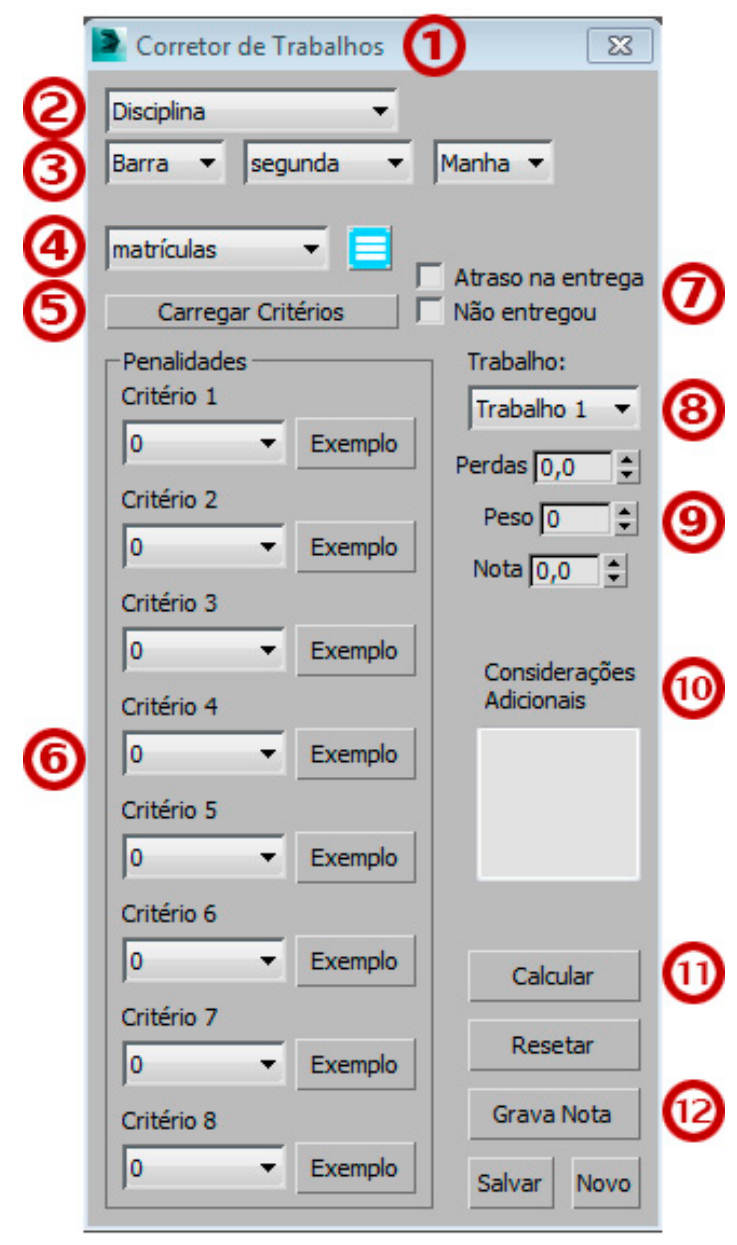

Figura 1 - Interface da ferramenta criada para o software 3ds Max.

Elaborada pelo autor, com base na pesquisa realizada.

Este item é de fundamental importância para o conceito do projeto, pois ele permitirá ao discente identificar os seus erros através de um feedback conferido pelo docente. Ao mesmo tempo, a seleção através desta ferramenta torna mais fácil e rápido para o docente o trabalho da correção, pois este pode verificar os critérios e avaliar o trabalho realizado no software 3D.

Cada item identificado realiza a seguinte função:

1 - A identificação dos discentes procura reconhecer as diferentes maneiras de representar o aluno utilizado pelas Universidades. Assim, criou-se uma função que abre um arquivo externo e reconhece cada nova linha deste arquivo como um novo aluno. Desta maneira, caso o docente queira, identificar um aluno por sua matrícula ele o conseguirá. Se quiser fazê-lo através de seu nome, isto também será possível.

A Identificação da Disciplina avaliada (2) é uma entrada de dados onde o docente seleciona a disciplina

Já o carregamento de informações acerca do feedback (6) é o módulo que torna esta ferramenta mais funcional, já que permite ao docente carregar todos os seus critérios de avaliação, através dos quais o docente poderá penalizar a avaliação do trabalho do aluno.

Finalmente há um módulo de penalização (7) que aplica um desconto por atraso na entrega indica se o discente entregou ou não seus trabalhos. Este faz uma 
operação matemática simples, somando todas as penalidades e as subtraindo da avaliação total.

Complementando a ferramenta há uma seção (módulo 10), cuja função é permitir que o docente comente o trabalho avaliado, podendo inserir informações adicionais às já visualizadas durante a avaliação do trabalho entregue.

\section{UTILIZAÇÃO}

Inicialmente o docente deve criar uma lista ordenada de seus alunos, identificando-os segundo os critérios utilizados pela instituição de ensino onde trabalha.

As informações referentes às disciplinas que serão avaliadas são carregadas automaticamente pelo sistema. Este input de dados é feito pelo Technical Director, mas poderá ser futuramente criada uma forma de interação onde os usuários carregarão os dados da instituição.

Para os dados dos alunos o método ainda é manual e o docente deve digitar uma lista com as informações de cada um, onde o script os reconhece através da quebra de linha, como mostrado na figura a seguir:

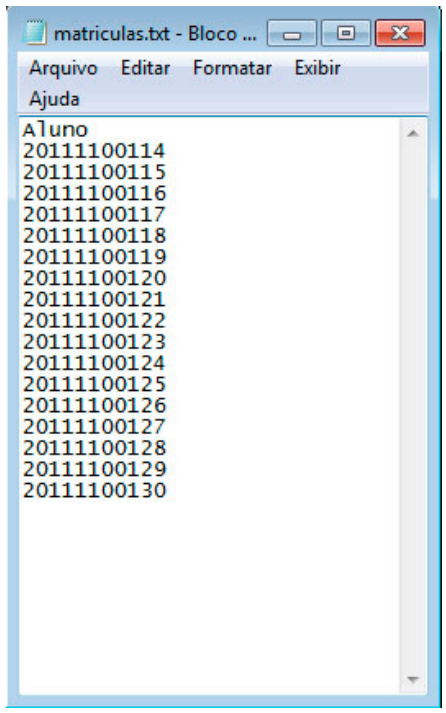

Figura 2 - Arquivo .txt contendo as matrículas dos alunos.

Elaborada pelo autor, com base na pesquisa realizada.

Os critérios de avaliação são preenchidos e carregados de maneira semelhante:

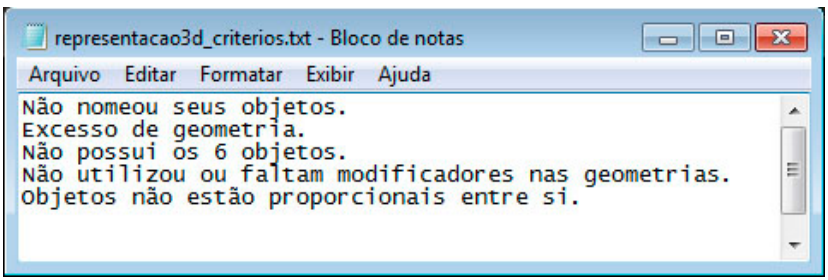

Figura 3 - Arquivo .txt contendo os critérios de avaliação da disciplina.

Elaborada pelo autor, com base na pesquisa realizada. 
A partir do carregamento dos critérios pelo Corretor de Trabalhos, o trabalho pode ser avaliado através do módulo 6 (figura 1), que reconhecerá os critérios e permitirá ao docente selecionar a geometria defeituosa através do botão entitulado "Exemplo".

Esta funcionalidade permite que o docente faça a avaliação de maneira mais rápida, pois não precisa digitar o nome da geometria nem a razão ao emitir seus comentários. Estas informações são gravadas diretamente no arquivo final de feedback.

Os cálculos de notas são feitos de maneira automatizada através do botão calcular nota, evitando erros por parte do docente. Mas, caso seja verificado que houve algum engano, pode-se retornar à situação anterior, selecionando a função "Resetar".

Uma área especial, denominada "Considerações adicionais" é o que permite ao docente complementar as funções automáticas presentes na ferramenta, oferecendo ao discente a oportunidade de receber um feedback qualitativo acerca de seu trabalho de maneira personalizada.

Ao gravar a avaliação através da funcionalidade "Gravar Nota" (módulo 12), o docente aciona uma função que armazena todas as informações em um array de dados encabeçado pela matrícula do aluno avaliado.

Após a realização de todos os feedbacks de uma turma o docente gravará as notas através de "Salvar Nota", gravando de uma vez todos os feedbacks em um arquivo texto, como o apresentado na figura abaixo, que poderá ser visualizado pelo aluno assim que disponibilizado pelo docente.

feedbacks.trt - Notepad

File Edit Format View Help

20161102875 | Nota: 9.5 | Não apresentou todos os 6 objetos com as 5 geometrias. Por exemplo: Box001. (-0,5 pontos)

20153101111 | Nota: 7.0 | Ultrapassou o número de polígonos permitidos para a cena|. (-0,5 pontos) | Não entregou no prazo ( -1.0 ponto).

Figura 4 - Arquivo .txt contendo os feedbacks retornados pelo sistema.

Elaborada pelo autor, com base na pesquisa realizada.

\section{FEEDBACK}

A apresentação de um feedback mesclado entre a personalização do docente e a automatização operacionalizada via computação é o resultado esperado da utilização da ferramenta, no qual todas as avaliações de trabalhos de discentes são exportadas para uma lista que é organizada de acordo com as identificações e a ordenação na lista de identificação.

Para o docente, possuir uma ferramenta que gere todos os feedbacks instantaneamente e de maneira ordenada torna suas tarefas eficientes, já que o mesmo não precisará se preocupar em seguir a seguinte sequência de eventos: abrir o software 3D, avaliar o trabalho, redigir um feedback para o discente (em um editor de textos), retornar ao software de 3D, e então passar ao próximo trabalho.

Ao executar um script inserido no software de 3D, as etapas apresentadas anteriormente são reduzidas a: abrir o software de 3D, avaliar o trabalho do aluno e gerar o feedback do aluno. 


\section{RESULTADOS E DISCUSSÃO}

Para um designer, realizar a etapa de programação de uma interface é uma tarefa árdua. Embora o Design seja um campo prático cuja atuação pode ser atrelada ao desenvolvimento de projetos tecnológicos, as bases de conhecimento necessárias à criação de algoritmos não são comumente lecionadas nas universidades, limitando a atuação do designer apenas ao projeto visual e de usabilidade de interfaces.

Em áreas emergentes, como as de disciplinas práticas ligadas ao audiovisual em especial, as representações gráficas 3D, frequentemente são necessários projetos que exigem conhecimentos de programação para aumentar a produtividade dos profissionais envolvidos nesta área de atuação. No mercado de trabalho são raros os profissionais (formados ou não) que possuem estas habilidades. Na academia esse gap é ainda mais acentuado.

Produzir tecnologia que alie a inserção do designer na área de programação para computação gráfica em 3D e ao mesmo tempo criar uma tecnologia que permita o aumento da eficiência docente foi um dos objetivos da criação deste script integrado ao software em questão, o 3ds Max.

A resolução de um problema que atinge grande parte dos docentes - a falta de tempo para se dedicar a outras atividades acadêmicas - especialmente em graduações tecnológicas, foi outro objetivo que tentamos atingir com o início deste projeto.

E por fim, objetivamos melhorar a qualidade do feedback oferecido ao aluno que, por ser iniciante na carreira, muitas vezes não consegue perceber os pontos onde precisa se aprimorar, auxiliando a identificação correta e precisa dos pontos onde este aprimoramento deverá ser realizado.

Pretende-se futuramente validação esta pesquisa através de testes com usuários docentes, o que deverá ser realizado com aqueles diretamente relacionados à disciplinas que utilizam em seus programas de ensino os softwares de modelagem 3D.

Esta é uma ferramenta construída recentemente, cuja conclusão foi realizada este ano, portanto, os resultados práticos ainda serão aferidos, mas acreditamos na eficiência desta para a melhoria nas condições de qualidade de vida do designer docente, além de proporcionar a este a oportunidade de utilizar seu tempo eficientemente na pesquisa e na elaboração de melhores métodos de ensino.

Acreditamos que o feedback, mesclado entre a automatização e a personalização, permitirá a melhoria no processo de aprendizado do aluno.

\section{CONCLUSÃO E TRABALHOS FUTUROS}

Acredita-se que esta ferramenta seja apenas um passo inicial rumo a uma direção que permitirá ao docente utilizar melhor seu tempo na elaboração de práticas de ensino mais eficientes, evitando que o mesmo invista seu tempo em tarefas repetitivas.

Além disso, espera-se que o desenvolvimento desta ferramenta caminhe na direção do desenvolvimento de novos módulos que, além da atuação do docente, possam ser utilizados para reconhecer os critérios de cada disciplina lecionada por este, tornando ainda mais eficaz a correção via scritps automatizados.

Futuramente planeja-se agregar outras funcionalidades à esta ferramenta, como funções de reconhecimento automático dos critérios utilizados pelo docente. 
Isto se dará através do trabalho conjunto entre docente e TD, em discussões onde serão aprimorados e adaptados os critérios para reconhecimento dos critérios adotados pelo docente.

Esses aprimoramentos deverão ser acompanhados de dois profissionais importantes neste processo: o docente, que definirá suas regras e critérios e o TD (ou o designer programador), que conhece a fundo o processo de criação de módulos em softwares de 3D. O trabalho de ambos conjugados oferecerá ferramentas a uma área cada vez mais importante e integrada na área de Motion Graphics e Animação dos curso de Design.

Um caminho alternativo seria a utilização do Corretor de Trabalhos em cursos de Educação à Distância oferecidos por faculdades de tecnologia. Neste caso, o desenvolvimento de novos módulos permitiria a correção automática por parte de cada instrutor. Isto também viabiliza a correção de trabalhos da área de 3D a docentes Designers não versados nessas áreas, ampliando seus campos de atuação.

Todo o código-fonte desta ferramenta encontra-se disponível para visualização em: https://drive.google.com/open?id=0B9k0V7loATF-QUJrS1VYMkJwQTg

\section{REFERÊNCIAS}

Autodesk 3ds Max 2014 Help. http://docs.autodesk.com/3DSMAX/16/ENU/MAXScriptHelp/. Acessado em 07/01/2014.

DEMO, P. Aprendemos pouco na faculdade.

https://docs.google.com/document/d/1clwPAkLCvnvQuUM8SrWPGIOrc6EUAOqOrpyo QUJHTOM/pub. Acessado em 03/01/2014.

MARINHO, R.A.A. O uso de avaliações escolares ordinárias para estudar a inovação da competência em física. 2010. 92f. Dissertação (mestrado) - Universidade Federal de Minas Gerais, Curso de Mestrado da Faculdade de Educação da UFMG.

OLIVEIRA, E. L. A., NARDIN, A. C. O uso do moodle como suporte às atividades de ensino/aprendizagem presencial em cursos técnicos integrados. XVI Jornada Nacional de Educação. Educação: Território de Saberes. Disponível em:http://jne.unifra.br/artigos/4848.pdf. Acessado em 22/02/2014.

ROMANOWSKI, J. Avaliação da Aprendizagem na educação à distância: análise da prática para início de conversa. Eccos, vol. 10, iss:2, pg.283-306, 2008

SCHÖN, D. A. The Reflective Practitioner. How Professionals Think in Action. Basic Books. United States: 1982. 